\title{
Dermoscopic features in different dermatopathological stages of cutaneous melanomas
}

\author{
Katarzyna Podolec, Agnieszka Bronikowska, Magdalena Pirowska, Anna Wojas-Pelc
}

Department of Dermatology, Jagiellonian University Medical College, Krakow, Poland

Adv Dermatol Allergol

DOI: https://doi.org/10.5114/ada.2019.83221

\begin{abstract}
Introduction: Due to the rising incidence of cutaneous melanoma there is a great need for the development of new diagnostic techniques as well as the improvement of those that are already well known, such as dermoscopy. Since early detection and a proper technique for excising the tumor are crucial for patients' survival, early staging of the tumor is very important.

Aim: To investigate whether there is a significant difference between the presence of selected dermoscopic features compared to the location on the skin and pathology results: Breslow's depth, mitotic index and ulceration.

Material and methods: We examined videodermoscopic images of cutaneous melanomas in 81 patients and compared their features with the histological results such as Breslow's depth, mitotic index and ulceration. In the study, we divided and compared the tumors in groups: in situ and invasive, $\leq 1.0 \mathrm{~mm}$ and $>1.0 \mathrm{~mm}$ thick on the Breslow scale.

Results: In the study we observed statistically significantly higher prevalence of pseudopods (30.5\%) and multicomponent pattern $(69.5 \%)$ in invasive melanomas in comparison to in situ melanomas $(9.1 \%$ and $36.4 \%$ respectively). White regression structures were more commonly described in invasive melanomas thicker than $1.0 \mathrm{~mm}$ on Breslow's scale. Atypical blood vessels and nodules were more specific to invasive melanomas with ulcerations and mitotic index $\geq 1$. The atypical pigment network was more specific for thin invasive melanomas.

Conclusions: Presence of pseudopods, a multicomponent pattern, white regression structures, atypical blood vessels and nodules on dermoscopy suggest invasive (high stage) melanoma.
\end{abstract}

Key words: dermoscopy, melanoma, cutaneous malignant melanoma.

\section{Introduction}

Due to the rising incidence of cutaneous melanoma in Europe and increasing social awareness, the number of patients who report to dermatologists in order to assess their skin changes is growing rapidly [1, 2]. For examining melanocytic skin lesions, dermoscopes have currently become the first-line diagnostic tools since they allow the in vivo examination of structures in the epidermis and superficial dermis which are not accessible for naked-eye examination [3-5].

The first detailed description of the microscopic assessment of the surface of the skin was presented by Saphier, who also introduced the term dermatoscopy for the first time in the 1920s. It was not until 1951 in the USA that Goldman first described the dermoscopic image of melanocytic nevi. The rapid development of dermoscopy as a method of assessing melanocytic changes in the skin occurred in the 1980s, mainly due to the work of Soyer and Pehamberger [6]. The next step was the introduction of videodermoscopy as a technique for recording and comparing images of selected skin lesions, enabling dermatologists to diagnose early stages of cutaneous melanoma [7].

In modern dermatological practice, dermoscopy (epiluminescent microscopy) is considered a non-invasive, easily reproducible and inexpensive method of the in vivo assessment of structures and colors within the epidermis and superficial dermis. It allows examination using 10-20x magnification - in traditional handheld dermoscopes - and 10-200×magnification in videodermoscopes [8]. Dermoscopy enables the clinician to examine plural diagnostic features in different skin lesions, which are normally impossible to detect with the naked eye. As a vastly researched technique it is known to have a high specificity of $\approx 65-90 \%$ and sensitivity evaluated

Address for correspondence: Katarzyna Podolec, Department of Dermatology, Jagiellonian University Medical College, 8 Skawinska St, 31-066 Krakow, Poland, phone: +48 501543 249, e-mail: kasiapodolec@gmail.com, katarzyna.podolec@uj.edu.pl Received: 9.11.2018, accepted: 20.01.2019. 
as $\approx 65-90 \%$ [9-11] if performed by a well-experienced clinician $[7,12]$.

Breslow's depth - described in the 1970s - is a method that allows the pathologist to assess the stage of melanoma by measuring the depth of infiltration in millimeters [13]. At first staging the cutoff was applied for Breslow's depth of $0.76 \mathrm{~mm}$, later updated by the American Joint Committee on Cancer to $1.0 \mathrm{~mm}$ (or $<1.0 \mathrm{~mm}$ when ulceration is present) $[13,14]$.

Advanced metastatic melanoma is still considered incurable in most cases, whereas early cutaneous melanomas are curable by means of surgical excision. According to guidelines in patients with cutaneous melanomas stage $\leq$ pT1a, surgical excision within the range $0.5-1 \mathrm{~cm}$ $[15,16]$ is considered curative. In patients with > pT1a melanomas, usually sentinel lymph node biopsy and often subsequent surgery remain unavoidable [15-17]. Even though there are plural emerging therapies introduced in the treatment of metastatic melanomas, it still remains the case that the more advanced the disease the worse the prognosis (overall survival) for the patients [18-20]. This is why an early, accurate diagnosis is crucial for positive outcomes. Nowadays, despite the emergence of diagnostic tools such as reflectance confocal microscopy [21-24], and optical coherence tomography [25], which have been described as being more specific and sensitive than dermoscopy $[24,26,27]$, their accessibility is still limited, and dermoscopy remains a first-line diagnostic tool for dermatologists $[25,28]$.

\section{Aim}

In the study, the goal was to decide whether there is a significant difference between the presence or absence of each of the dermoscopic features listed in Table 1 [2931], compared to the location on the skin and pathology results: Breslow's depth, mitotic index and ulceration.

\section{Material and methods}

In our study, we retrospectively evaluated videodermoscopic images of histopathologically confirmed melanomas in 81 patients that were diagnosed and examined at the Dermatology Department, Jagiellonian University Medical College in Krakow, Poland. The dermoscopic images were acquired using videodermoscopes (Fotofinder, TeachScreen GmbH, Bad Birnbach, Germany). For every lesion a set of at least 3 images was acquired. Entire lesions were photographed using 20x magnification. In addition, local features of tumors were photographed using maximum 120× magnification. The image data were collected between 2013 and 2017. The evaluation was conducted by two dermatologists with a minimum of 6 years' experience in general dermatology and dermoscopy. For the purpose of blinding the images were anonymized. For all the evaluated tumors, the patients' data were collected, including: age (at the time of diagnosis), sex, location of the primary tumor, Breslow's depth, the histological subtype of melanoma, mitotic index and information on the presence/absence of ulceration.

The examining dermatologists evaluated the lesions assessing the presence or absence of the following dermoscopic features: white regression structures; peppering; blue-white veil; atypical blood vessels/atypical vascular structures; atypical pigment network; atypical dots and globules; irregular streaks; a multicomponent (complex) pattern; pseudopods and nodules. The definitions of listed structures are available in Table 1.

Table 1. Definitions of dermoscopic structures evaluated in the study [29-31]

\begin{tabular}{|c|c|}
\hline Pigment network & $\begin{array}{l}\text { Light-to-dark brown fishnet-like pattern appearing on pathology melanocytes at dermo-epidermal } \\
\text { junction (melanocytes forming lines of network with dermal papillae forming "holes") }\end{array}$ \\
\hline Atypical pigment network & Atypical black/gray/brown network with thickened mesh and plural irregularities \\
\hline Atypical dots and globules & $\begin{array}{l}\text { Asymmetrically distributed brown/ black and gray dots }(\leq 0.1 \mathrm{~mm}) \text {, round and oval structures } \\
\text { (globules) representing the accumulation of melanin (most commonly in melanocytes but sometimes } \\
\text { also in melanophages) - most commonly in melanocytic "nests" }\end{array}$ \\
\hline Blue-white veil & $\begin{array}{l}\text { Unstructured areas in blue-grayish/blue-whiteish color; with ground glass appearance. Represents } \\
\text { compact aggregation of melanocytes with concomitant orthokeratosis }\end{array}$ \\
\hline Streaks & Atypical, irregular linear structures that are not connected to pigment network \\
\hline White regression structures & $\begin{array}{l}\text { Whiteish depigmentation (lighter than adjacent skin); scar-like structures. Represent regression } \\
\text { structures and fibrosis in advanced melanomas }\end{array}$ \\
\hline Peppering & $\begin{array}{l}\text { Represent regression structures with the presence of melanophages forming a dermoscopic image } \\
\text { of black-grayish dots }\end{array}$ \\
\hline Nodules & Elevated structures within the lesion (corresponding to large blue, black and brown clods) \\
\hline $\begin{array}{l}\text { Atypical blood vessels/ } \\
\text { atypical vascular structures }\end{array}$ & Pinkish erythema in regression structures/dotted and irregular linear blood vessels \\
\hline Multicomponent pattern & $\begin{array}{l}\geq 3 \text { areas representing different dermoscopic features in a single lesion. Usually combined with } \\
\text { asymmetry in malignant lesions }\end{array}$ \\
\hline
\end{tabular}


In the study, we evaluated the association between the presence of the dermoscopic structures (listed in Table 1) and histopathological stage of melanoma - by dividing tumors into: in situ, thin invasive tumors (using cutoff at $\leq 1.0 \mathrm{~mm}$ ) and thick invasive tumors (cutoff at $>1.0 \mathrm{~mm}$ ). We also assessed the predictors in accordance with the mitotic index ( 0 or $\geq 1)$ and presence of ulceration.

Dermoscopic images of acral, nail apparatus, spitzoid and amelanotic melanomas were excluded due to differences in the dermoscopic picture of such tumors.

\section{Results}

The group of patients consisted of 44 men and 37 women aged (at the day of diagnosis) between 26 and 97 with the average being 61.4 and the median being 63 .

Regarding the distribution of the lesions, 14 (17.28\%) were found on the head, 37 (45.68\%) on the trunk, 16 (19.75\%) on the upper limbs and 14 (17.28\%) on the lower limbs.

Twenty-two (27.16\%) of 81 melanomas were in situ, and 59 (72.84\%) were invasive. On pathology examina-

Table 2. Frequency of various dermoscopic features depending on the location on the skin (head, trunk, upper and lower limbs)

\begin{tabular}{|c|c|c|c|c|c|c|c|c|c|c|c|c|}
\hline \multirow[t]{3}{*}{ Parameter } & & \multicolumn{11}{|c|}{ Tumor location } \\
\hline & & \multicolumn{2}{|c|}{ Head } & \multicolumn{2}{|c|}{ Trunk } & \multicolumn{2}{|c|}{ Upper limbs } & \multicolumn{2}{|c|}{ Lower limbs } & \multicolumn{2}{|c|}{ Total } & \multirow{2}{*}{$\begin{array}{c}\begin{array}{c}\chi^{2} ; \\
p \text {-value }\end{array} \\
0.94 ;\end{array}$} \\
\hline & & $N$ & $\%$ & $N$ & $\%$ & $N$ & $\%$ & $N$ & $\%$ & $N$ & $\%$ & \\
\hline \multirow{3}{*}{$\begin{array}{l}\text { White } \\
\text { regression } \\
\text { structures }\end{array}$} & Absent & 2 & 14.29 & 8 & 21.62 & 1 & 6.25 & 4 & 28.57 & 15 & 18.52 & \\
\hline & Present & 12 & 85.71 & 29 & 78.38 & 15 & 93.75 & 10 & 71.43 & 66 & 81.48 & \\
\hline & Total & 14 & 100.00 & 37 & 100.00 & 16 & 100.00 & 14 & 100.00 & 81 & 100.00 & \\
\hline \multirow[t]{3}{*}{ Peppering } & Absent & 3 & 21.43 & 19 & 51.35 & 9 & 56.25 & 9 & 64.29 & 40 & 49.38 & \multirow{3}{*}{$\begin{array}{l}5.98 \\
0.113\end{array}$} \\
\hline & Present & 11 & 78.57 & 18 & 48.65 & 7 & 43.75 & 5 & 35.71 & 41 & 50.62 & \\
\hline & Total & 14 & 100.00 & 37 & 100.00 & 16 & 100.00 & 14 & 100.00 & 81 & 100.00 & \\
\hline \multirow[t]{3}{*}{ Blue-white veil } & Absent & 5 & 35.71 & 16 & 43.24 & 5 & 31.25 & 6 & 42.86 & 32 & 39.51 & \multirow{3}{*}{$\begin{array}{l}0.82 \\
0.844\end{array}$} \\
\hline & Present & 9 & 64.29 & 21 & 56.76 & 11 & 68.75 & 8 & 57.14 & 49 & 60.49 & \\
\hline & Total & 14 & 100.00 & 37 & 100.00 & 16 & 100.00 & 14 & 100.00 & 81 & 100.00 & \\
\hline \multirow{3}{*}{$\begin{array}{l}\text { Atypical blood } \\
\text { vessels }\end{array}$} & Absent & 10 & 71.43 & 20 & 54.05 & 7 & 43.75 & 7 & 50.00 & 44 & 54.32 & \multirow{3}{*}{$\begin{array}{l}2.48 \\
0.479\end{array}$} \\
\hline & Present & 4 & 28.57 & 17 & 45.95 & 9 & 56.25 & 7 & 50.00 & 37 & 45.68 & \\
\hline & Total & 14 & 100.00 & 37 & 100.00 & 16 & 100.00 & 14 & 100.00 & 81 & 100.00 & \\
\hline \multirow{3}{*}{$\begin{array}{l}\text { Atypical } \\
\text { pigment } \\
\text { network }\end{array}$} & Absent & 8 & 57.14 & 8 & 21.62 & 8 & 50.00 & 3 & 21.43 & 27 & 33.33 & \multirow{3}{*}{$\begin{array}{l}8.75 \\
0.033\end{array}$} \\
\hline & Present & 6 & 42.86 & 29 & 78.38 & 8 & 50.00 & 11 & 78.57 & 54 & 66.67 & \\
\hline & Total & 14 & 100.00 & 37 & 100.00 & 16 & 100.00 & 14 & 100.00 & 81 & 100.00 & \\
\hline \multirow{3}{*}{$\begin{array}{l}\text { Irregular dots } \\
\text { and globules }\end{array}$} & Absent & 7 & 50.00 & 7 & 18.92 & 5 & 31.25 & 5 & 35.71 & 24 & 29.63 & \multirow{3}{*}{$\begin{array}{l}5.09 \\
0.165\end{array}$} \\
\hline & Present & 7 & 50.00 & 30 & 81.08 & 11 & 68.75 & 9 & 64.29 & 57 & 70.37 & \\
\hline & Total & 14 & 100.00 & 37 & 100.00 & 16 & 100.00 & 14 & 100.00 & 81 & 100.00 & \\
\hline \multirow[t]{3}{*}{ Irregular streaks } & Absent & 8 & 57.14 & 18 & 48.65 & 6 & 37.50 & 4 & 28.57 & 36 & 44.44 & \multirow{3}{*}{$\begin{array}{l}2.92 \\
0.404\end{array}$} \\
\hline & Present & 6 & 42.86 & 19 & 51.35 & 10 & 62.50 & 10 & 71.43 & 45 & 55.56 & \\
\hline & Total & 14 & 100.00 & 37 & 100.00 & 16 & 100.00 & 14 & 100.00 & 81 & 100.00 & \\
\hline \multirow{3}{*}{$\begin{array}{l}\text { Multicomponent } \\
\text { pattern }\end{array}$} & Absent & 7 & 50.00 & 11 & 29.73 & 10 & 62.50 & 4 & 28.57 & 32 & 39.51 & \multirow{3}{*}{$\begin{array}{l}6.36 \\
0.095\end{array}$} \\
\hline & Present & 7 & 50.00 & 26 & 70.27 & 6 & 37.50 & 10 & 71.43 & 49 & 60.49 & \\
\hline & Total & 14 & 100.00 & 37 & 100.00 & 16 & 100.00 & 14 & 100.00 & 81 & 100.00 & \\
\hline \multirow[t]{3}{*}{ Pseudopods } & Absent & 14 & 100.00 & 28 & 75.68 & 12 & 75.00 & 7 & 50.00 & 61 & 75.31 & \multirow{3}{*}{$\begin{array}{l}9.42 \\
0.024\end{array}$} \\
\hline & Present & 0 & 0 & 9 & 24.32 & 4 & 25.00 & 7 & 50.00 & 20 & 24.69 & \\
\hline & Total & 14 & 100.00 & 37 & 100.00 & 16 & 100.00 & 14 & 100.00 & 81 & 100.00 & \\
\hline \multirow[t]{3}{*}{ Nodules } & Absent & 12 & 85.71 & 23 & 62.16 & 12 & 75.00 & 11 & 78.57 & 58 & 71.60 & 3.42 \\
\hline & Present & 2 & 14.29 & 14 & 37.84 & 4 & 25.00 & 3 & 21.43 & 23 & 28.40 & \\
\hline & Total & 14 & 100.00 & 37 & 100.00 & 16 & 100.00 & 14 & 100.00 & 81 & 100.00 & \\
\hline
\end{tabular}


Table 3. Frequency of various dermoscopic features of in situ and invasive melanomas

\begin{tabular}{|c|c|c|c|c|c|c|}
\hline Variable & $\begin{array}{c}\text { Invasive melanoma } \\
n(\%)\end{array}$ & $\begin{array}{c}\text { Melanoma in situ } \\
n(\%)\end{array}$ & $P$-value & OR $(95 \% \mathrm{Cl})$ & Sensitivity & Specificity \\
\hline White regression structures & $48(81.4)$ & $18(81.8)$ & 0.962 & $1.03(0.29-3.66)$ & & \\
\hline Peppering & $28(47.5)$ & $13(59.1)$ & 0.352 & $1.60(0.59-4.31)$ & & \\
\hline Blue-white veil & $37(62.7)$ & $12(54.5)$ & 0.504 & $0.71(0.26-1.92)$ & & \\
\hline Atypical blood vessels & $27(45.8)$ & $10(45.5)$ & 0.980 & $0.99(0.37-2.64)$ & & \\
\hline Atypical pigment network & $39(66.1)$ & $15(68.2)$ & 0.860 & $1.10(0.39-3.13)$ & & \\
\hline Irregular dots and globules & $45(76.3)$ & $12(54.5)$ & 0.057 & $0.37(0.13-1.05)$ & & \\
\hline Irregular streaks & $35(59.3)$ & $10(45.5)$ & 0.264 & $0.57(0.21-1.53)$ & & \\
\hline Multicomponent pattern & $41(69.5)$ & $8(36.4)$ & 0.007 & $0.25(0.09-0.70)$ & 83.7 & 43.8 \\
\hline Pseudopods & $18(30.5)$ & $2(9.1)$ & 0.047 & $0.23(0.05-1.08)$ & 90.0 & 32.8 \\
\hline Nodules & 20 (33.9) & 3 (13.6) & 0.072 & $0.31(0.08-1.17)$ & & \\
\hline
\end{tabular}

tion in 6 (7.5\%) tumors ulceration was detected and in 23 (28.4\%) lesions the mitotic index was $\geq 1$.

Comparison of the prevalence of the listed dermoscopic features (Table 1) between male and female patients showed a statistically significantly higher prevalence of atypical blood vessels and a multicomponent pattern in female patients (62.2 and $73 \%$ respectively; $p<0.005$ ).

Assessing the relation between evaluated dermoscopic structures and different locations of primary tumors (head, trunk, lower limbs, and upper limbs) (Table 2) we found that pseudopods were most commonly present on the lower limbs (50\%), less commonly on the trunk and upper limbs (24.32\% and $25 \%$ respectively; $p$ $=0.024)$. An atypical network was described in $66.67 \%$ of all tumors, ranging between $78.57 \%$ and $78.38 \%$ on the lower limbs and trunk, and $42.86 \%$ and $50 \%$ on the head and upper limbs (Figure 1).

In situ melanomas showed a significantly lower frequency of pseudopods and multicomponent pattern

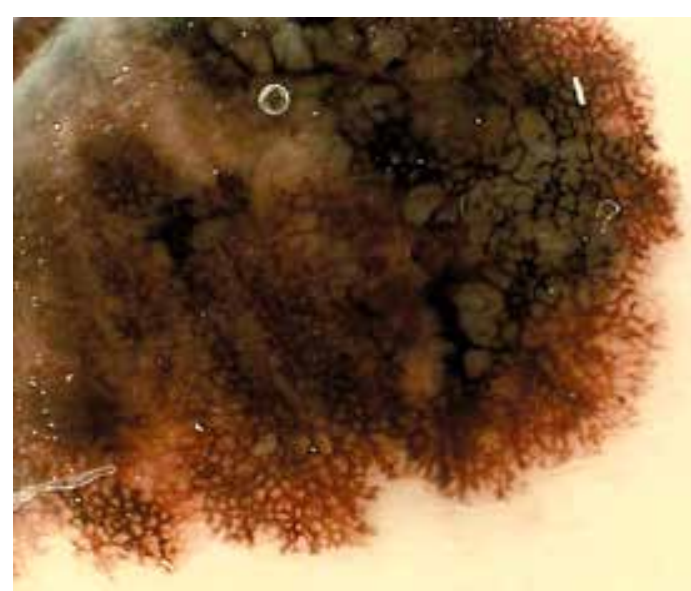

Figure 1. Atypical network and pseudopods in invasive melanoma of the lower limb
(9.1\% and 36.4\%) in comparison with invasive tumors with $30.5 \%$ and $69.5 \%$ positive for pseudopods and multicomponent pattern (Table 3).

Tumors thicker than $1.0 \mathrm{~mm}$ showed a higher prevalence of white regression structures with $22.7 \%$ sensitivity, though $100 \%$ specificity. An atypical network was observed in $46.7 \%$ of tumors $>1.0 \mathrm{~mm}$ thick and in $71.2 \%$ of thinner tumors, though the difference was not statistically significant (Figure 2 ). In $60 \%$ of melanomas $>1.0$ $\mathrm{mm}$ thick and $21.2 \%$ of melanomas $\leq 1.0 \mathrm{~mm}$ nodules were described in dermoscopy.

The study also showed a negative correlation between the positive mitotic index and an atypical network, and positive correlation between $\mathrm{MI} \geq 1$ and nodules as well as a positive correlation for presence of ulceration and atypical blood vessels/vascular structures and nodules on dermoscopy.

\section{Discussion}

The last three decades have brought rapid development of diagnostic tools in dermato-oncology. Due to

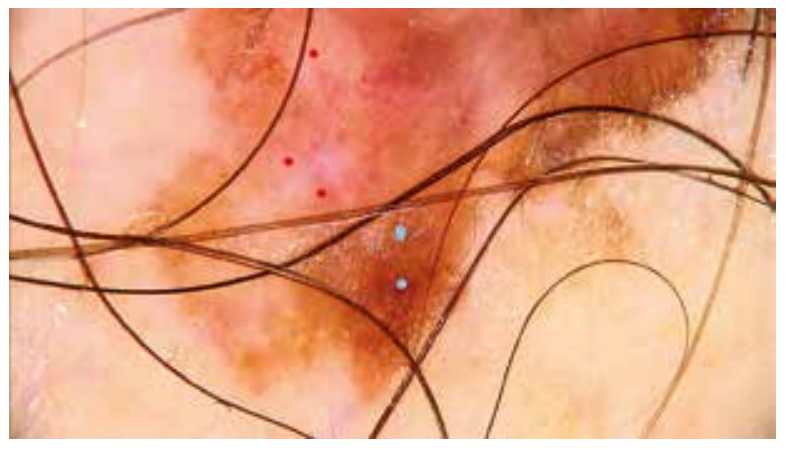

Figure 2. Atypical network (blue dots), white regression structures and atypical blood vessels (red dots) in invasive melanoma of the trunk 
Table 4. Frequency of dermoscopic features in melanomas $\leq 1.0 \mathrm{~mm}$ and $>1.0 \mathrm{~mm}$ on Breslow's depth

\begin{tabular}{|c|c|c|c|c|c|c|}
\hline Variable & $\begin{array}{c}\text { Breslow } \leq 1.0 \mathrm{~mm} \\
n(\%)\end{array}$ & $\begin{array}{c}\text { Breslow }>1.0 \mathrm{~mm} \\
n(\%)\end{array}$ & $P$-value & OR $(95 \% \mathrm{Cl})$ & Sensitivity & Specificity \\
\hline White regression structures & $51(77.3)$ & $15(100.0)$ & 0.041 & - & 22.7 & 100.0 \\
\hline Peppering & $35(53.0)$ & $6(40.0)$ & 0.362 & $0.59(0.19-1.85)$ & - & - \\
\hline Blue-white veil & $38(57.6)$ & $11(73.3)$ & 0.260 & $2.03(0.58-7.03)$ & - & - \\
\hline $\begin{array}{l}\text { Atypical blood vessels/atypical } \\
\text { vascular structures }\end{array}$ & $28(42.4)$ & $9(60.0)$ & 0.217 & $2.04(0.65-6.38)$ & - & - \\
\hline Atypical pigment network & $47(71.2)$ & $7(46.7)$ & 0.069 & $0.35(0.11-1.11)$ & - & - \\
\hline Atypical dots and globules & $45(68.2)$ & $12(80.0)$ & 0.366 & $1.87(0.48-7.32)$ & - & - \\
\hline Streaks & $40(60.6)$ & $5(33.3)$ & 0.055 & $0.33(0.10-1.06)$ & - & - \\
\hline Multicomponent pattern & 39 (59.1) & $10(66.7)$ & 0.588 & $1.38(0.43-4.51)$ & - & - \\
\hline Pseudopods & $19(28.8)$ & $1(6.7)$ & 0.073 & $0.18(0.02-1.44)$ & - & - \\
\hline Nodules & $14(21.2)$ & $9(60.0)$ & 0.003 & $5.57(1.70-18.31)$ & 39.1 & 89.7 \\
\hline
\end{tabular}

Table 5. Mean Breslow's depth in melanomas divided into groups depending on the presence/absence of dermoscopic features

\begin{tabular}{|c|c|c|c|c|c|c|c|}
\hline Variable & $\begin{array}{c}\text { Traits absent }^{1} \\
\text { Mean Breslow } \\
\pm \text { SD }\end{array}$ & $\begin{array}{l}\text { Traits present }{ }^{1} \\
\text { Mean Breslow } \\
\pm \text { SD }\end{array}$ & $P$-value ${ }^{2}$ & OR $(95 \% \mathrm{Cl})$ & Cutpoint & Sensitivity & Specificity \\
\hline White regression structures & $0.35 \pm 0.30$ & $1.10 \pm 2.64$ & 0.255 & $2.41(0.74-7.87)$ & - & - & - \\
\hline Peppering & $0.80 \pm 0.93$ & $1.12 \pm 3.26$ & 0.095 & $1.06(0.86-1.31)$ & - & - & - \\
\hline Blue-white veil & $0.77 \pm 1.42$ & $1.08 \pm 2.88$ & 0.335 & $1.07(0.85-1.35)$ & - & - & - \\
\hline $\begin{array}{l}\text { Atypical blood vessels/atypical } \\
\text { vascular structures }\end{array}$ & $0.62 \pm 0.88$ & $1.37 \pm 3.40$ & 0.457 & $1.25(0.85-1.82)$ & - & - & - \\
\hline Atypical pigment network & $1.86 \pm 3.96$ & $0.51 \pm 0.64$ & 0.040 & $0.55(0.32-0.95)$ & 0.375 & 70.3 & 59.3 \\
\hline Atypical dots and globules & $0.85 \pm 1.62$ & $1.01 \pm 2.68$ & 0.399 & $1.03(0.82-1.29)$ & - & - & - \\
\hline Streaks & $1.47 \pm 3.50$ & $0.55 \pm 0.60$ & 0.821 & $0.69(0.43-1.12)$ & - & - & - \\
\hline Multicomponent pattern & $0.77 \pm 1.45$ & $1.08 \pm 2.87$ & 0.176 & $1.07(0.85-1.35)$ & - & - & - \\
\hline Pseudopods & $1.11 \pm 2.75$ & $0.49 \pm 0.34$ & 0.921 & $0.68(0.34-1.38)$ & - & - & - \\
\hline Nodules & $0.57 \pm 1.03$ & $1.93 \pm 4.11$ & 0.030 & $1.52(0.96-2.43)$ & 0.375 & 60.9 & 53.4 \\
\hline
\end{tabular}

${ }^{1}$ Traits - dermoscopy features: white regression structures, peppering, blue-white veil, atypical blood vessels/atypical vascular structures, atypical pigment network, atypical dots and globules, streaks, multicomponent pattern, pseudopods, nodules. P-value-statisticaly significant if $<0.05$.

their accessibility, dermoscopy and videodermoscopy are the most commonly used diagnostic techniques in the early diagnosis of cutaneous melanoma [8, 32]. In order to standardize dermoscopic examinations specific diagnostic features, as well as criteria, have been described. The most popular algorithms applied in the dermoscopic diagnosis of melanoma are: pattern analysis [6], ABCD criteria [9, 33, 34], and the 7-point checklist [3, 35]. Knowing the listed criteria allows the early detection of cutaneous melanomas by an experienced dermoscopist in contrast to naked-eye examination. It would be extremely useful if it could also help clinicians to determine the tumor stage or Breslow's depth, in order to simplify the planning of excisions and possible sentinel lymph node biopsies.

In previous studies, there have been a few attempts to examine the possible correlations between the pres- ence of distinct dermoscopic features and tumor thickness, though the results are contradictory.

In a study on 123 melanomas (including only tumors with a Breslow's depth of > 0.75), González-Álvarez et al. observed a correlation of dermoscopic ulcerations and blotches with positive sentinel lymph node biopsy results and the presence of an atypical pigment network with negative sentinel lymph node biopsy results [36]. Pizzichetta et al. examined and compared dermoscopic images of in situ melanomas and invasive melanomas (subdivided into two groups $\leq 0.75 \mathrm{~mm}$ and $>0.75 \mathrm{~mm}$ ), finding a lower prevalence of atypical pigment network and pseudopods in thick invasive melanomas (>0.75 mm) in comparison with in situ melanomas, as well as greater relative numbers of pseudopods, brown globules, grayblue areas, and depigmentation in in situ lesions com- 


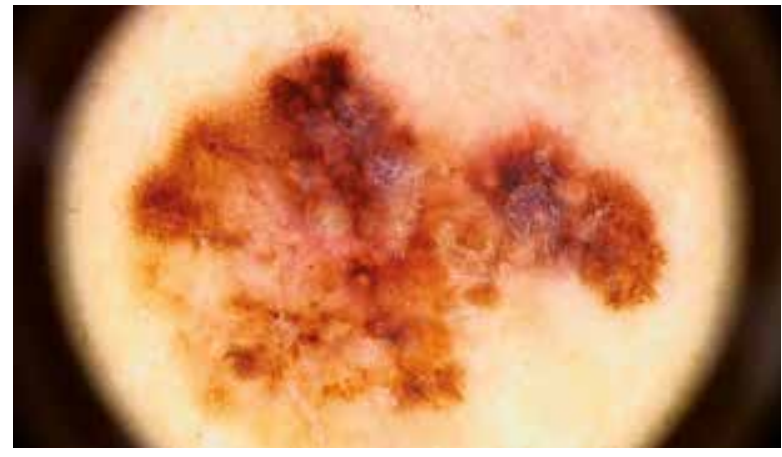

Figure 3. Multicomponent pattern in invasive melanoma of the trunk

pared with invasive melanomas with a Breslow's depth of $\leq 0.75 \mathrm{~mm}$. On the other hand, Menzies et al., researching the morphologic criteria of pseudopods in 80 melanomas (62 invasive and 18 in situ) and 159 randomly selected pigmented nonmelanomas, observed higher prevalence of the structures in invasive melanomas in comparison to in situ tumors. Pseudopods retained $97 \%$ specificity, though only $23 \%$ sensitivity [37]. Emiroglu et al., researching only trunk melanomas (71 cases), found no correlation between dermoscopic image and Breslow's depth [38].

In our study using univariate regression analysis, we compared the prevalence of the listed dermoscopic features (Table 1) between male and female patients, and found a significantly higher prevalence of atypical blood vessels and a multicomponent pattern in female patients (62.2\% and $73 \%$ respectively; $p<0.005)$. The analysis showed no significant differences in different age groups.

The $\chi^{2}$ analysis was performed to assess the relation between evaluated dermoscopic structures and different locations of primary tumors (head, trunk, lower limbs, and upper limbs) (Table 2). There were no significant differences in the presence of regression, peppering, atypical blood vessels, atypical dots and globules, multicomponent pattern or nodules. Pseudopods were present in $24.69 \%$ of all evaluated tumors; most commonly they were observed on the lower limbs (50\%), less commonly on the trunk and upper limbs (24.32\% and 25\% respectively; $p=0.024)$. An atypical network was described in $66.67 \%$ of all tumors, ranging between $78.57 \%$ and $78.38 \%$ on the lower limbs and trunk, and $42.86 \%$ and $50 \%$ on the head and upper limbs.

In order to analyze possible relationships between the presence of the listed dermoscopic features and histopathologic stage of melanomas, the Mann-Whitey $U$ test and Student's $t$ test were used. In situ melanomas were evaluated separately as well as tumors presenting Breslow's depth $\leq 1 \mathrm{~mm}$ and $>1 \mathrm{~mm}$ to check for differences in frequency of appearance of distinct dermoscopic structures. No statistically significant differences regarding the prevalence of peppering, blue-white veil, atypical dots and globules, atypical blood vessels or streaks were noted (Table 4). In situ melanomas showed a significantly lower frequency of pseudopods and multicomponent pattern (9.1\% and $36.4 \%$ ) in comparison with invasive tumors (Figure 3) - with 30.5\% and 69.5\% positive for pseudopods and multicomponent pattern (Table 3).

We have calculated mean Breslow's depth in melanomas divided into groups depending on the presence/ absence of dermoscopic features. Tumors with a visible atypical pigment network had a significantly lower mean Breslow's depth in comparison to melanomas presenting no atypical pigment network. Melanomas presenting with nodules, on the other hand, had greater Breslow's depth in comparison to tumors presenting no nodules on dermoscopy (Table 5).

Taking into account the guidelines updated by the American Joint Committee on Cancer (as well as many European, including Polish), we compared thick and thin melanomas assuming a cutoff point at $1.0 \mathrm{~mm}$ Breslow's depth. Tumors thicker than $1.0 \mathrm{~mm}$ showed a higher prevalence of white regression structures with $22.7 \%$ sensitivity, though $100 \%$ specificity. An atypical network was observed in $46.7 \%$ of tumors $>1.0 \mathrm{~mm}$ thick and in $71.2 \%$ of thinner tumors, though the difference was not statistically significant. In $60 \%$ of melanomas $>1.0 \mathrm{~mm}$ thick and $21.2 \%$ of melanomas $\leq 1.0 \mathrm{~mm}$ nodules were described in dermoscopy. Specificity of this feature was $89.7 \%$ in thick melanomas and sensitivity $39.1 \%(p=0.003 ; \mathrm{OR}=5.57)$.

Considering the fact that the mitotic index was removed from AJCC guidelines in 2018, and replaced with ulceration, but is still applied in melanoma staging and grading in many European countries [14, 15, 39], we analyzed the presence of dermoscopic structures in melanomas with a negative mitotic index in comparison to melanomas with $\mathrm{MI} \geq 1$. The Mann-Whitey $U$ test showed a negative correlation between the positive mitotic index and an atypical network, and a positive correlation between $\mathrm{MI} \geq 1$ and nodules.

Controlling for ulceration in pathology, we found a positive correlation for atypical blood vessels/vascular structures and nodules with low sensitivity (13.9\% and $18.2 \%$ respectively; $p<0.05)$ but high specificity.

\section{Conclusions}

The presence of an atypical network may point the examining dermatologist towards the diagnosis of thin invasive melanoma, whereas pseudopods, a multicomponent pattern, white regression structures, atypical blood vessels, and nodules suggest invasive (high stage) melanoma. Thus the presence of such dermoscopic structures should alert the examining dermatologist. Dermoscopy is a very useful method in the early diagnosis of cutaneous melanoma, especially in regard to early, non- metastatic 
tumors. It may also provide some insight into the metastatic potential of detected tumors.

\section{Conflict of interest}

The authors declare no conflict of interest.

\section{References}

1. Nikolaou V, Stratigos AJ. Emerging trends in the epidemiology of melanoma. Br J Dermatol 2014; 170: 11-9.

2. Erdmann F, Lortet-Tieulent J, Schüz J, et al. International trends in the incidence of malignant melanoma 1953-2008are recent generations at higher or lower risk? Int J Cancer 2013; 132: 385-400.

3. Vestergaard ME, Macaskill P, Holt PE, Menzies SW. Dermoscopy compared with naked eye examination for the diagnosis of primary melanoma: a meta-analysis of studies performed in a clinical setting. Br J Dermatol 2008; 159: 669-76.

4. Stolz W, Bilek P, Landthaler M, et al. Skin surface microscopy. Lancet 1989; 334: 864-5.

5. Braun RP, Rabinovitz HS, Oliviero M, et al. Dermoscopy of pigmented skin lesions. J Am Acad Dermatol 2005; 52: 109-21.

6. Pehamberger H, Steiner A, Wolff K. In vivo epiluminescence microscopy of pigmented skin lesions. I. Pattern analysis of pigmented skin lesions. J Am Acad Dermatol 1987; 17: 571-83.

7. Carli P, De Giorgi V, Crocetti E, et al. Improvement of malignant/benign ratio in excised melanocytic lesions in the "dermoscopy era": a retrospective study 1997-2001. Br J Dermatol 2004; 150: 687-92.

8. Sheu SL, Cho HG, Nord KM. Videodermoscopy as a novel tool for dermatologic education. Cutis 2017; 100: E25-7.

9. Thomas L, Tranchand P, Berard F, et al. Semiological value of ABCDE criteria in the diagnosis of cutaneous pigmented tumors. Dermatology 1998; 197: 11-7.

10. Russo T, Piccolo V, Ferrara G, et al. Dermoscopy pathology correlation in melanoma. J Dermatol 2017; 44: 507-14.

11. Argenziano G, Fabbrocini G, Carli P, et al. Epiluminescence microscopy for the diagnosis of doubtful melanocytic skin lesions. Arch Dermatol 1998; 134: 1563-70.

12. Rao BK, Marghoob AA, Stolz W, et al. Can early malignant melanoma be differentiated from atypical melanocytic nevi by in vivo techniques? Ski Res Technol 1997; 3: 8-14.

13. Breslow A, Washington G. Thickness, cross-sectional areas and depth of invasion in the prognosis of cutaneous melanoma. https://www-1ncbi-1nlm-1nih-1gov-1nb5yei4p0743. hanproxy.cm-uj.krakow.pl/pmc/articles/PMC1397358/pdf/ annsurg00406-0132.pdf. Accessed September 15, 2018.

14. Key Changes in the AJCC Eighth Edition Melanoma Staging System - SkinCancer.org. https://www.skincancer.org/publications/the-melanoma-letter/2018-vol-36-no-1/ajcc-stagingsystem. Accessed September 15, 2018.

15. Rutkowski P, Wysocki JP, Nasierowska-Guttmejer A, et al. Cutaneous melanoma - guidelines for diagnostics and therapy in 2016. Dermatol Rev 2016; 102: 1-18.

16. Fleming MD, Galan A, Gastman B, et al. Aim at Melanoma NCCN Guidelines Version 3.2018 Melanoma.; 2018. https:// www.nccn.org/professionals/physician_gls/PDF/melanoma. pdf. Accessed September 17, 2018.

17. Koseła H, Świtaj T, Rutkowski P, et al. Przypadki kliniczne chorych na zaawansowane czerniaki leczonych ipilimumabem. Onkol Prakt Klin 2015; 11: A1-8.
18. Crocetti E, Mallone S, Robsahm TE, et al. Survival of patients with skin melanoma in Europe increases further: results of the EUROCARE-5 study. Eur J Cancer 2015; 51: 2179-90.

19. Survival Rates for Melanoma Skin Cancer, by Stage. https:// www.cancer.org/cancer/melanoma-skin-cancer/detectiondiagnosis-staging/survival-rates-for-melanoma-skin-cancerby-stage.html. Accessed September 17, 2018.

20.Balch CM, Soong SJ, Gershenwald JE, et al. Prognostic factors analysis of 17,600 melanoma patients: validation of the American Joint Committee on Cancer Melanoma Staging System. J Clin Oncol 2001; 19: 3622-34.

21. Wielowieyska-Szybińska D, Białek-Galas K, Podolec K, WojasPelc $A$. The use of reflectance confocal microscopy for examination of benign and malignant skin tumors. Postep Dermatol Alergol 2014; 31: 380-7.

22. Guitera P, Pellacani G, Crotty KA, et al. The impact of in vivo reflectance confocal microscopy on the diagnostic accuracy of lentigo maligna and equivocal pigmented and nonpigmented macules of the face. I Invest Dermatol 2010; 130: 2080-91.

23. Longo C, Moscarella E, Argenziano G, et al. Reflectance confocal microscopy in the diagnosis of solitary pink skin tumours: review of diagnostic clues. Br J Dermatol 2015; 173: 31-41.

24. Pellacani G, Pepe P, Casari A, Longo C. Reflectance confocal microscopy as a second-level examination in skin oncology improves diagnostic accuracy and saves unnecessary excisions: a longitudinal prospective study. Br I Dermatol 2014; 171: 1044-51.

25. De Carvalho N, Welzel J, Schuh S, et al. The vascular morphology of melanoma is related to Breslow index: an in vivo study with dynamic optical coherence tomography. Exp Dermatol 2018; 27: 1280-6.

26. Borsari S, Pampena R, Benati E, et al. In vivo dermoscopic and confocal microscopy multistep algorithm to detect in situ melanomas. Br J Dermatol 2018; 179: 163-72.

27. Ferrari B, Pupelli G, Farnetani F, et al. Dermoscopic difficult lesions: an objective evaluation of reflectance confocal microscopy impact for accurate diagnosis. J Eur Acad Dermatology Venereol 2015; 29: 1135-40.

28. Serban ED, Farnetani F, Pellacani G, Constantin MM. Role of in vivo reflectance confocal microscopy in the analysis of melanocytic lesions. Acta Dermatovenerol Croat 2018; 26: 64-7.

29. Kittler H, Marghoob AA, Argenziano G, et al. Standardization of terminology in dermoscopy/dermatoscopy: results of the third consensus conference of the International Society of Dermoscopy HHS Public Access. J Am Acad Dermatol 2016; 74: 1093-106.

30. Micantonio T, Neri L, Longo C, et al. A new dermoscopic algorithm for the differential diagnosis of facial lentigo maligna and pigmented actinic keratosis. Eur J Dermatol 2018; 28 : 162-8.

31. Russo T, Piccolo V, Ferrara G, et al. Dermoscopy pathology correlation in melanoma. J Dermatol 2017; 44: 507-14.

32. Salerni G, Carrera C, Lovatto L, et al. Benefits of total body photography and digital dermatoscopy ("two-step method of digital follow-up") in the early diagnosis of melanoma in patients at high risk for melanoma. J Am Acad Dermatol 2012; 67: e17-27.

33. Nachbar F, Stolz W, Merkle T, et al. The ABCD rule of dermatoscopy. High prospective value in the diagnosis of doubtful melanocytic skin lesions. J Am Acad Dermatol 1994; 30 : 551-9. 
34. Rigel DS, Russak J, Friedman R. The evolution of melanoma diagnosis: 25 years beyond the ABCDs. CA Cancer J Clin 2010; 60: 301-16.

35. Menzies SW. A method for the diagnosis of primary cutaneous melanoma using surface microscopy. Dermatol Clin 2001; 19: 299-305.

36. González-Álvarez T, Carrera C, Bennassar A, et al. Dermoscopy structures as predictors of sentinel lymph node positivity in cutaneous melanoma. Br J Dermatol 2015; 172: 1269-77.

37. Menzies SW, Crotty KA, McCarthy WH. The morphologic criteria of the pseudopod in surface microscopy. Arch Dermato 1995; 131: 436-40.

38. Emiroglu N, Cengiz FP, Hofmann-Wellenhof R. Dermoscopic and clinical features of trunk melanomas. Adv Dermatol Allergol 2014; 31: 362-7.

39. Gershenwald JE, Scolyer RA, Hess KR, et al. Melanoma staging: evidence-based changes in the American Joint Committee on Cancer eighth edition cancer staging manual. CA Cancer J Clin 2017; 67: 472-92. 